\title{
Effect of different kinematics and operational temperature on cyclic fatigue resistance of rotary NiTi systems
}

\author{
Amira Galal Ismail ${ }^{1 *}$, Manar Galal ${ }^{1}$ and Mohamed Mokhtar Nagy ${ }^{2}$
}

\begin{abstract}
Background: The aim of this study was to compare the effect of different kinematics and operational temperature on cyclic fatigue resistance of Protaper Next, WaveOne Gold, and Twisted File Adaptive files in a static model.

Methodology: An artificial canal, made of stainless steel with an inner diameter of $1.5 \mathrm{~mm}$, a $60^{\circ}$ angle of curvature, and a curvature radius of $2 \mathrm{~mm}$, was used for the cyclic fatigue test immersed in a water bath for temperature adjustment $\left(37^{\circ} \mathrm{C}\right.$ and $20^{\circ} \mathrm{C}$ ). A total of 120 files were divided into three groups according to the type of motion continuous rotation motion (CRM), adaptive motion (AM), and reciprocation motion (RM). Each group was further subdivided into two subgroups according to the operational temperature $\left(37^{\circ} \mathrm{C}\right.$ and $\left.20^{\circ} \mathrm{C}\right)$, All instruments were operated until fracture occurred, and the time to fracture was recorded in seconds. Mean number of cycles to failure and standard deviations were calculated for each group, and data were analyzed statistically using two-way ANOVA followed by Tukey's post hoc test $(P \leq 0.05)$.

Results: The continuous rotation motion exhibited significantly lower cyclic fatigue resistance than reciprocating or adaptive motion $(p \leq 0.001)$ at $37^{\circ} \mathrm{C}$ and $20^{\circ} \mathrm{C}$.

Conclusions: Cyclic fatigue resistance of NiTi files was affected by the motion used during root canal preparation. Reciprocation motion and adaptive motion resulted in extended fatigue. The operational temperature affects the cyclic fatigue resistance of the twisted file.
\end{abstract}

Keywords: Adaptive motion, Body temperature, Continuous rotation, Cyclic fatigue, Kinematics, Reciprocation, Metallurgy, Alloys

\section{Introduction}

The introduction of rotary nickel-titanium (NiTi) instruments in endodontic practice has revolutionized the concept of root canal instrumentation in the last two decades. This is because of the alloy's superelasticity associated with the reversible phase transformation between austensite and martensite phases (Shen et al. 2013; Pereira et al. 2012; Brantley et al. 2009).

The clinical behavior of these two phases is remarkably different and temperature dependent (Otsuka and

\footnotetext{
* Correspondence: amirgalal@gmail.com

${ }^{1}$ Researcher of Endodontics, Restorative and Dental Material Department,

National Research Centre, Cairo, Egypt

Full list of author information is available at the end of the article
}

Ren 2005). Originally, the development of NiTi systems has been focused on changes in file design together with the simplification of the instrumentation sequences without changing the basic properties of the alloy (Shen et al. 2013; Peters and Paque 2010). More recently, new heat treatment methods together with novel manufacturing procedures have been introduced to improve the cyclic fatigue resistance of the rotary files (Plotino et al. 2017; Gambarini et al. 2008; Rodrigues et al. 2011).

Another approach adopted by the manufacturers to improve the cyclic fatigue resistance of the instruments is changing the rotation kinematics during root canal preparation (Çapar and Arslan 2016). Reciprocation motion was introduced to reduce stress values attained by

\section{Springer Open}


the instrument during rotation through travelling to a shorter angular distance than rotation motion do (Silva et al. 2016; Plotino et al. 2015). Meanwhile, the adaptive motions is composed of both continuous and reciprocation motion. When the amount of stress on the file is kept to minimal, the file continues in constant rotation until substantial load is applied; hence, reciprocation motion is executed (Marks Duarte et al. 2018).

Fracture of endodontic rotary instruments occurs due to combination between torsional and flexural fatigue. Torsional fracture occurs due to locking of the tip or any part of the instrument in the canal, while the shaft continues to rotate. Flexural fatigue occurs when the instrument rotates inside a curved root canal and is subjected to an excessive number of tension-compression strain cycles in the region of maximum root canal curvature (Pedullà et al. 2018). The environmental temperature dramatically affects fatigue resistance of nickel-titanium rotary files (Plotino et al. 2017; Grande et al. 2017).

The aim of the present study was to compare the effect of different kinematics on cyclic fatigue resistance of Protaper Next (PTN), WaveOne Gold (WOG), and Twisted File Adaptive (TFA) files in room temperature.

\section{Materials and methods}

Based on data from previous studies (Plotino et al. 2017; De Vasconcelos et al. 2016), a power calculation was performed using the G*Power 3.1 software (Faul et al. 2007) (Heinrich Heine University, Dusseldorf, Germany). The calculation indicated that the sample size for each group should be a minimum of 20 files. A total of 120 files were tested for cyclic fatigue failure, twenty files from each system; TFA; SM2 (SybronEndo, Orange, CA, USA), PTN; X2 (Dentsply Maillefer, Ballaigues, Switzerland); and WOG; primary file (Dentsply Maillefer, Ballaigues, Switzerland). The instruments were inspected for any manufacturing defects using a stereomicroscope (Olympus BX43; Olympus Co, Tokyo, Japan).

A specially designed custom-made cyclic fatigue testing device was used in this study (Fig. 1). This device consisted of curved stainless steel canal $19 \mathrm{~mm}$ in length with $60^{\circ}$ angle of curvature and $2 \mathrm{~mm}$ radius, which were stuck on an acrylic surface where the headpiece was also fixed. The radius and angle of curvature were determined according to Pruett et al. (Pruett et al. 1997). To reduce friction between the instrument and the metal canal walls, a synthetic oil was used as a lubricant. The artificial canals were covered with glass to prevent the instruments from slipping out.

The method described by De Vasconcelos et al. (De Vasconcelos et al. 2016) was used to adjust the operating temperature. The device was placed in a glass water container, with rotating the instruments until fracture in air.

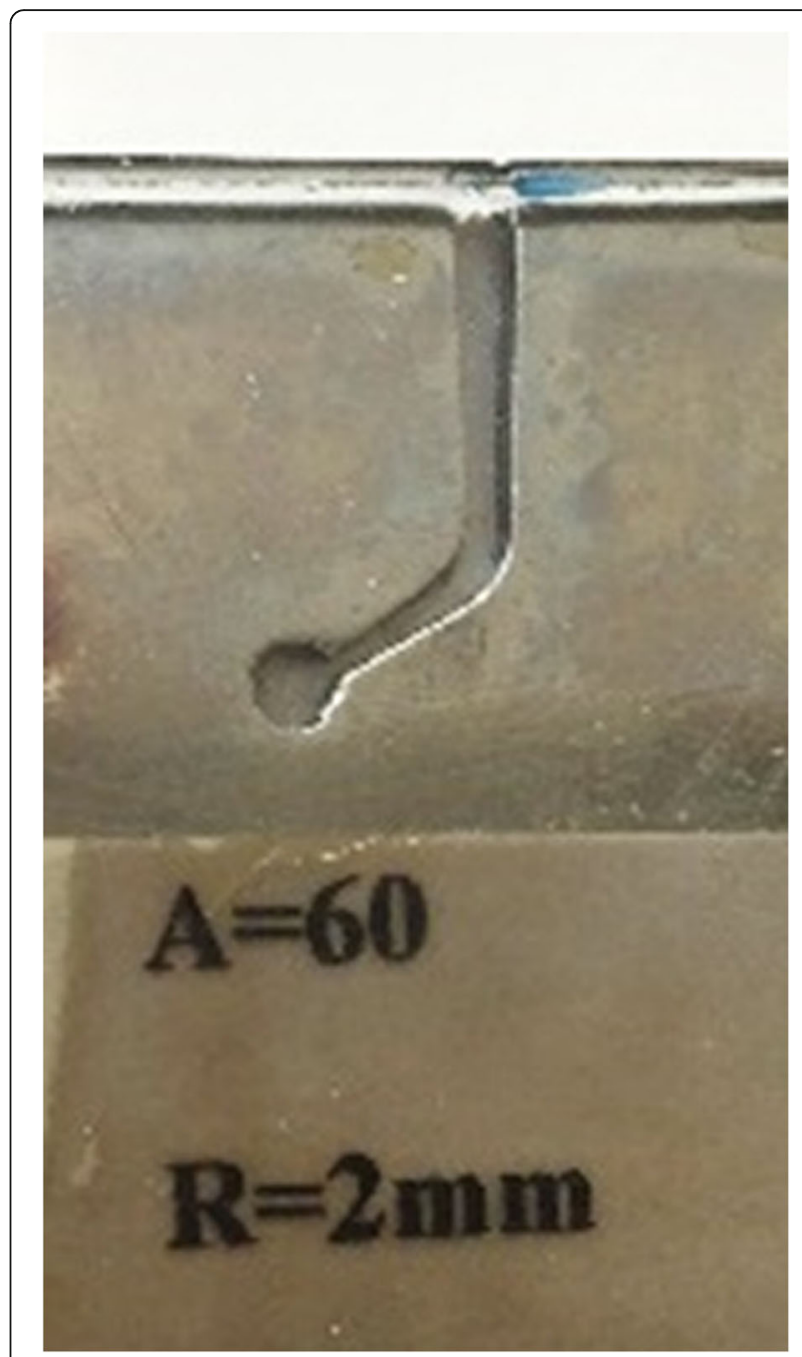

Fig. 1 A custom-made cyclic fatigue testing device

The glass container was filled with $200 \mathrm{~mL}$ water and immersed in ice until the water temperature was stabilized at $20 \pm 1{ }^{\circ} \mathrm{C}$ or placed on a hot plate until the water temperature was stabilized at $37 \pm 1{ }^{\circ} \mathrm{C}$, and the temperature was continuously monitored using an infrared thermometer (Etekcity Corporation, CA, USA).

The files were divided into three groups $(n=20)$, and the following procedures were performed:

\section{Group (RM): reciprocation motion}

The WOG primary files $25 / .07(n=20)$ were inserted into the artificial canal and operated using a torquecontrolled endodontic motor ( $\mathrm{x}$-smart plus, Dentsply, Maillefer) following the instructions given by the manufacturer at $350 \mathrm{rpm}$, reciprocating motion until fracture.

\section{Group (AM): adaptive motion}

The TFA files SM2 25/.06 $(n=20)$ were inserted into the artificial canal and operated with the "TF Adaptive" 
program, using electric motor (SybronEndo, Glendora, CA, USA) following the instructions given by the manufacturer at $400 \mathrm{rpm}$ until fracture.

\section{Group (CRM): continuous rotation motion}

The PTN X2 files $(n=20)$ were inserted into the artificial canal and operated using a torque-controlled endodontic motor ( $x$-smart plus, Dentsply, Maillefer) following the instructions given by the manufacturer at $300 \mathrm{rpm}$, continuous rotation motion until fracture.

The time to fracture was recorded in seconds using a stopwatch and stopped as soon as a fracture was detected visually, and a video recording was performed to cross-check the time of file separation.

The number of cycles to failure (NCF) was calculated by multiplying the rpm (in seconds) with the time taken to fracture (in seconds). NCF data were analyzed by using one-way ANOVA followed by Tukey's post hoc test. Statistical analysis was performed using the software SPSS (Statistical Packages for the Social Sciences 20.0; IBM, Armonk, NY).

\section{Results}

The mean NCF and standard deviations for all groups are shown in Table 1.

There was a statistically significant difference between (AM), (RM), and (CRM) $(p \leq 0.001)$ at $37^{\circ} \mathrm{C}$ and $20^{\circ} \mathrm{C}$.

At $20^{\circ} \mathrm{C}$, the highest fatigue resistance was recorded in group (RM) Wave One gold followed by group (AM), TF adaptive without significant difference, whereas the lowest fatigue resistance was recorded in group (CRM) Protaper Next which was significantly lower.

At $37^{\circ} \mathrm{C}$, the highest fatigue resistance was recorded in group (RM) Wave One Gold followed by group (AM), TF adaptive with significant decrease, whereas the lowest fatigue resistance was recorded in group (CRM) Protaper Next which was significantly lower.

Regarding the effect of temperature, the RM group (Wave One Gold) and RCM group (Protaper Next) showed no significant decrease in NCF with raising the temperature to $37^{\circ} \mathrm{C}$. However, the AM group (Twisted file) recorded significant decrease in NCF at $37^{\circ} \mathrm{C}$.

Table 1 The mean and standard deviation (SD) of the number of cycles to failure (NCF) for different groups

\begin{tabular}{lllll}
\hline & Group (AM) & Group (RM) & Group (RCM) & $P$ value \\
\hline $20 \pm 1^{\circ} \mathrm{C}$ & $728 \pm 151^{\mathrm{aA}}$ & $850 \pm 130^{\mathrm{aA}}$ & $388 \pm 40^{\mathrm{bA}}$ & $P \leq 0.001$ \\
$37 \pm 1^{\circ} \mathrm{C}$ & $568 \pm 63^{\mathrm{bB}}$ & $833 \pm 138^{\mathrm{aA}}$ & $347 \pm 29^{\mathrm{CA}}$ & $P \leq 0.001$ \\
$P$ value & $P \leq 0.001$ & $P=0.397$ & $P \leq 0.085$ & \\
\hline
\end{tabular}

Significant at $p<0.05$

Different superscript small letters indicate statistically significance difference between different groups in the same row

Different superscript capital letters indicate statistically significance difference between different subgroups in the same column

\section{Discussion}

Several factors affect NiTi file fracture during endodontic treatment of curved root canals such as kinematics, speed used, structural characteristics, method of manufacturing, geometric designs, radius, and angle of the curvature of the canal (Castelló-Escrivá et al. 2012; Kim et al. 2008).

The aim of the present study was to compare the effect of different kinematics on cyclic fatigue resistance of Protaper Next, WaveOne Gold, and TF Adaptive files in a static model at different operational temperatures.

According to Yao et al. (Yao et al. 2006), to decrease the influence of other variables, standardized artificial canals in custom made device should be used. Therefore, in the present study, a standardized artificial canal was used for the cyclic fatigue test, and this was in full agreement with De-Deus et al. (De-Deus et al. 2010).

A static model was used in this study rather than a dynamic model. Although the dynamic model could mimic the clinical brushing or pecking motion, it has limitations because the instruments are not constrained in a precise trajectory. Moreover, the speed and amplitude of the axial movements are subjective because this up and down motion is manually controlled (Pedullà et al. 2018; Higuera et al. 2015).

The results of this study showed that the highest cyclic fatigue resistance was associated with the reciprocation motion followed by adaptive motion then continuous rotation. This might indicate that the motion plays a major role in cyclic fatigue resistance. These findings might be attributed to the release of the reaction stresses built up in the material by reversing the rotational direction (Gavini et al. 2012; You et al. 2010). Plotino et al. (Plotino et al. 2014) concluded that reciprocating movement can improve cyclic fatigue resistance of $\mathrm{NiTi}$ instruments by reducing torsional loads and torsional failure.

On the other hand, the adaptive motions are composed of continuous and reciprocation motion. When the amount of stress on the file is minimal, the file uses continuous rotation till load is applied, and it then uses reciprocation motion (Higuera et al. 2015); thus, TFA has been shown to be elastic and resistant to cyclic fatigue than continuous rotation motion did (De-Deus et al. 2010; Bhagabati et al. 2012).

A number of studies (Gambarini et al. 2012; Karataş et al. 2016; Keskin et al. 2017; Gündoğar and Özyürek 2017) reported that, regardless of the file type, reciprocation motion increased the cyclic fatigue resistance of files more than continuous rotation did. Karatas et al. (Karataş et al. 2016) concluded that fatigue life is associated with the number of times that a crack in an instrument closes and opens. During reciprocation motions, the instrument needs to complete one full rotation (360) in more time when compared with continuous rotation. 
Therefore, the number of times that a crack closes and opens in reciprocation motions is expected to be less when compared with continuous rotation or adaptive motions over the same time. This may explain the extended fatigue life of reciprocation motion. This was in full agreement with the results of the present study as the PTN showed the least cyclic resistance among the tested groups.

WOG file has a parallelogram cross-sectional design with only two cutting edges, and this design in addition to high austenitic finish value and 2-stage transformation behavior decreases the torsional stress on the file and extends its cyclic fatigue resistance as described by Özyürek (Gündoğar and Özyürek 2017; Özyürek 2016). Although TFA file has a triangular cross-section design with three cutting edges that thought to increase the torsional stress on the file decreasing its cyclic fatigue resistance, yet, the unique heat treatment (R-phase) coupled with electropolishing (Castelló-Escrivá et al. 2012) might maintain the natural grain structure resulted in decreased crack initiation and propagation process. Hence, the file has comparable cyclic fatigue resistance coupled with the novel adaptive motion operational mode.

Although PTN file has the same parallelogram crosssection design as WOG, it showed significant difference in cyclic fatigue resistance than WOG and TFA files. These results emphasized that the motion plays a major role in cyclic fatigue resistance than the design do.

Another important issue to be emphasized is the operational temperature. It was found that the temperature inside the root canal is buffered within few minutes to $31-35^{\circ} \mathrm{C}$ as stated by De Hemptinne et al. (De Hemptinne et al. 2015). So, our study was performed comparing the two environmental temperatures. It was found that raising the temperature from room temperature to body temperature considerably reduced the cyclic fatigue resistance for both PTN and TFA rotary systems. These findings are in agreement with recent previous studies (Plotino et al. 2017; Grande et al. 2017; De Vasconcelos et al. 2016; Yılmaz et al. 2018).

The considerable decrease in fatigue resistance might be due to the interrelated transformation temperatures, austenitic finish temperature, in which raising the temperature to around $37^{\circ} \mathrm{C}$ suggests that the instrument is typically in an austenitic state. This is evident for TFA in which the austenitic finish temperature was identified to be about $20^{\circ} \mathrm{C}$ (Braga et al. 2013), whereas in Wave One Gold and the M-Wire Protaper Next, the transformation temperature obviously above body temperature is about $50^{\circ} \mathrm{C}$ (Ye and Gao 2012; Hieawy et al. 2015); accordingly, the files were not affected by the increase of temperature during cyclic fatigue testing in the present study which was in full agreement with Plotino et al. (Plotino et al. 2017)

\section{Conclusion}

Under the conditions of this study, it can be concluded that:

1. The operational temperature at which the instruments are tested has a considerable effect on cyclic fatigue testing and varies according to the type of alloy.

2. Gold heat treated alloys and M-wire alloys are not readily affected by the intracanal temperature because their austenitic temperature is obviously above body temperature, whereas Twisted file is influenced by intracanal temperature because its austenitic finish is below body temperature.

3. The mode of rotation greatly affects the cyclic fatigue, whereas both the reciprocation and adaptive motions exhibited higher cyclic fatigue resistance than continuous rotation.

\section{Abbreviations}

NiTi: Nickel titanium; PTN: Protaper Next; WOG: WaveOne Gold; TFA: Twisted File Adaptive; SPSS: Statistical Packages for social sciences; ANOVA: Analysis of variance; CRM: Continuous rotation motion; AM: Adaptive motion; RM: Reciprocating motion; NCF: Number of cycles to failure;

RPM: Revolutions per minute

\section{Acknowledgements}

Not applicable

\section{Authors' contributions}

Amira Galal Ismail prepared specimens and analyzed and interpreted data. Manar Galal wrote the manuscript. Mohamed Mokhtar Nagy analyzed the data and substantively revised the work. The authors read and approved the final manuscript.

\section{Authors' information}

Dr. Amira Galal is a graduate and postgraduate (Msc, phD) of Cairo

University, School of Oral and Dental Medicine. She is currently a researcher of Endodontics, Restorative and Dental Material department at the National Research Centre. Dr. Amira is also an FDI speaker and has lectured extensively nationally and internationally. Moreover, she has published articles in local and international Journals.

\section{Funding}

None

Availability of data and materials

- The datasets used and/or analyzed during the current study are available from the corresponding author on reasonable request.

- All data generated or analyzed during this study are included in this published article.

Ethics approval and consent to participate

Not applicable

Consent for publication

Not applicable

\section{Competing interests}

No competing interest in this section.

\section{Author details}

${ }^{1}$ Researcher of Endodontics, Restorative and Dental Material Department, National Research Centre, Cairo, Egypt. ${ }^{2}$ Associate professor, Endodontic Department, Faculty of Dentistry, Ain Shams University, Cairo, Egypt. 
Received: 28 February 2020 Accepted: 22 June 2020

Published online: 13 July 2020

\section{References}

Bhagabati N, Yadav S, Talwar S (2012) An in vitro cyclic fatigue analysis of different endodontic nickel-titanium rotary instruments. J Endod. 38(4):515-518

Braga LC, Magalhães RRS, Nakagawa RKL, Puente CG, Buono VTL, Bahia MGA (2013) Physical and mechanical properties of twisted or ground nickeltitanium instruments. Int Endod J. 46(5):458-465

Brantley WA, Liu J, Clark WAT, Kovarik L, Buie C, lijima M, et al. Characterization of new nickel-titanium wire for rotary endodontic instruments. In: Ceramic Transactions. 2009. p. 49-57.

Capar ID, Arslan H (2016) A review of instrumentation kinematics of engine-driven nickel-titanium instruments. International Endodontic Journal 49:119-135

Castelló-Escrivá R, Alegre-Domingo T, Faus-Matoses V, Román-Richon S, FausLlácer VJ (2012) In vitro comparison of cyclic fatigue resistance of ProTaper, WaveOne, and twisted files. J Endod. 38(11):1521-1524

De Hemptinne F, Slaus G, Vandendael M, Jacquet W, De Moor RJ, Bottenberg P (2015) In vivo intracanal temperature evolution during endodontic treatment after the injection of room temperature or preheated sodium hypochlorite. J Endod. 41(7):1112-1115

De Vasconcelos RA, Murphy S, Carvalho CAT, Govindjee RG, Govindjee S, Peters OA (2016) Evidence for reduced fatigue resistance of contemporary rotary instruments exposed to body temperature. J Endod. 42(5):782-787

De-Deus G, Moreira EJL, Lopes HP, Elias CN (2010) Extended cyclic fatigue life of F2 ProTaper instruments used in reciprocating movement. Int Endod J. 43(12):1063-1068

Faul F, Erdfelder E, Lang AG, Buchner A. G*Power 3: A flexible statistical power analysis program for the social, behavioral, and biomedical sciences. In: Behavior Research Methods. 2007. p. 175-91.

Gambarini G, Grande NM, Plotino G, Somma F, Garala M, De Luca M et al (2008) Fatigue Resistance of engine-driven rotary nickel-titanium instruments produced by new manufacturing methods. J Endod. 34(8):1003-1005

Gambarini G, Gergi R, Naaman A, Osta N, Al SD (2012) Cyclic fatigue analysis of twisted file rotary NiTi instruments used in reciprocating motion. Int Endod J. 45(9):802-806

Gavini G, Caldeira CL, Akisue E, Candeiro GTDM, Kawakami DAS (2012) Resistance to flexural fatigue of reciproc R25 files under continuous rotation and reciprocating movement. J Endod. 38(5):684-687

Grande NM, Plotino G, Silla E, Pedullà E, DeDeus G, Gambarini G et al (2017) Environmental temperature drastically affects flexural fatigue resistance of nickel-titanium rotary files. J Endod. 43(7):1157-1160

Gündoğar M, Özyürek T (2017) Cyclic fatigue resistance of OneShape, HyFlex EDM, WaveOne Gold, and Reciproc Blue Nickel-titanium instruments. J Endod. 43(7):1192-1196

Hieawy A, Haapasalo M, Zhou H, Wang ZJ, Shen Y (2015) Phase transformation behavior and resistance to bending and cyclic fatigue of ProTaper Gold and ProTaper Universal instruments. J Endod. 41(7):1134-1138

Higuera O, Plotino G, Tocci L, Carrillo G, Gambarini G, Jaramillo DE (2015) Cyclic fatigue resistance of 3 different nickel-titanium reciprocating instruments in artificial canals. J Endod. 41(6):913-915

Karataş E, Arslan H, Büker M, Seçkin F, Çapar ID (2016) Effect of movement kinematics on the cyclic fatigue resistance of nickel-titanium instruments. Int Endod J. 49(4):361-364

Keskin C, Inan U, Demiral M, Keleş A (2017) Cyclic Fatigue Resistance of Reciproc Blue, Reciproc, and WaveOne Gold Reciprocating Instruments. J Endod. 43(8): 1360-1363

Kim HC, Cheung GSP, Lee CJ, Kim BM, Park JK, Kang S (2008) II. Comparison of forces generated during root canal shaping and residual stresses of three nickel-titanium rotary files by using a three-dimensional finite-element analysis. J Endod. 34(6):743-747

Marks Duarte P, Barcellos da Silva P, Alcalde MP, Vivan RR, da Rosa RA, Duarte MAH et al (2018) Canal transportation, centering ability, and cyclic fatigue promoted by Twisted File Adaptive and Navigator EVO instruments at different motions. J Endod. 44(9):1425-1429

Otsuka K, Ren X (2005) Physical metallurgy of Ti-Ni-based shape memory alloys. Prog Mater Sci. 50(5):511-678

Özyürek T (2016) Cyclic fatigue resistance of Reciproc, WaveOne, and WaveOne Gold Nickel-Titanium instruments. J Endod. 42:1536-1539

Pedullà E, Corsentino G, Ambu E, Rovai F, Campedelli F, Rapisarda S et al (2018) Influence of continuous rotation or reciprocation of Optimum Torque
Reverse motion on cyclic fatigue resistance of nickel-titanium rotary instruments. Int Endod J. 51(5):522-528

Pereira ESJ, Peixoto IFC, Viana ACD, Oliveira II, Gonzalez BM, Buono VTL et al (2012) Physical and mechanical properties of a thermomechanically treated NiTi wire used in the manufacture of rotary endodontic instruments. Int Endod J. 45(5):469-474

Peters O, Paque F (2010) Current developments in rotary root canal instrument technology and clinical use: a review. Quintessence Int. 41(6):479-488

Plotino G, Giansiracusa Rubini A, Grande NM, Testarelli L, Gambarini G (2014) Cutting efficiency of reciproc and waveone reciprocating instruments. J Endod. 40(8):1228-1230

Plotino G, Ahmed HMA, Grande NM, Cohen S, Bukiet F (2015) Current assessment of reciprocation in endodontic preparation: a comprehensive review - Part II: Properties and Effectiveness. Journal of Endodontics 41:1939-1950

Plotino G, Grande NM, Mercadé Bellido M, Testarelli L, Gambarini G (2017) Influence of temperature on cyclic fatigue resistance of ProTaper Gold and ProTaper Universal Rotary Files. J Endod. 43(2):200-202

Pruett JP, Clement DJ, Carnes DL (1997) Cyclic fatigue testing of nickel-titanium endodontic instruments. J Endod. 23(2):77-85

Rodrigues RCV, Lopes HP, Elias CN, Amaral G, Vieira VTL, De Martin AS (2011) Influence of different manufacturing methods on the cyclic fatigue of rotary nickel-titanium endodontic instruments. J Endod. 37(11):1553-1557

Shen Y, Zhou HM, Zheng YF, Peng B, Haapasalo M (2013) Current challenges and concepts of the thermomechanical treatment of nickel-titanium instruments. J Endod. 39(2):163-172

Silva EJNL, Villarino LS, Vieira VTL, Accorsi-Mendonça T, Antunes HDS, De-Deus G et al (2016) Bending resistance and cyclic fatigue life of Reciproc, Unicone, and WaveOne Reciprocating instruments. J Endod. 42(12):1789-1793

Yao JH, Schwartz SA, Beeson TJ (2006) Cyclic fatigue of three types of rotary nickel-titanium files in a dynamic model. J Endod. 32(1):55-57

Ye J, Gao Y (2012) Metallurgical characterization of M-Wire nickel-titanium shape memory alloy used for endodontic rotary instruments during low-cycle fatigue. J Endod. 38(1):105-107

Yılmaz K, Uslu G, Gündoğar M, Özyürek T, Grande NM, Plotino G (2018) Cyclic fatigue resistances of several nickel-titanium glide path rotary and reciprocating instruments at body temperature. Int Endod J. 51(8):924-930

You SY, Bae KS, Baek SH, Kum KY, Shon WJ, Lee W (2010) Lifespan of one nickeltitanium rotary file with reciprocating motion in curved root canals. J Endod. 36(12):1991-1994

\section{Publisher's Note}

Springer Nature remains neutral with regard to jurisdictional claims in published maps and institutional affiliations.

\section{Submit your manuscript to a SpringerOpen ${ }^{\circ}$ journal and benefit from:}

- Convenient online submission

- Rigorous peer review

- Open access: articles freely available online

- High visibility within the field

- Retaining the copyright to your article

Submit your next manuscript at $\boldsymbol{\nabla}$ springeropen.com 